\title{
Co-Teaching in the "Academia Class": Evaluation of Advantages and Frequency of Practices
}

\author{
Edni Neifeald ${ }^{1} \&$ Yonit Nissim ${ }^{1}$ \\ ${ }^{1}$ Ohalo Acdemic College, Israel \\ Correspondence: Yonit Nissim, Ohalo Acdemic College, Israel. \\ Received: December 6, 2018 \\ Accepted: January 16, 2019 \\ Online Published: April 29, 2019 \\ doi:10.5539/ies.v12n5p86 \\ URL: https://doi.org/10.5539/ies.v12n5p86
}

\begin{abstract}
This article constitutes the continuation of a research process that investigated models and methods for co-teaching in the "Academia Class" program in the Ohalo Academic College (Nissim \& Naifeld, 2018). The article focuses on the contribution of this program to all those who participated in it, identifying co-teaching practices and the connections between the sense of contribution and identification of those practices. The research relied on the collection and analysis of quantitative data. The research population included 125 respondents, $51(40.8 \%)$ schoolteachers, $36(28.8 \%)$ student-teachers studying general education, 18 (14.4\%) kindergarten teachers and $20(16.0 \%)$ student-teachers studying early childhood education.

Three main research questions guided the investigation:

1) To what extent does each group of participants in the program estimate that co-teaching methods are advantageous for the teachers/kindergarten teachers, student teachers and pupils?

2) Which prevalent co-teaching practices are used in the Academia Class program?

3) Is there a correlation between the respondents' attitudes concerning the advantages of co-teaching and the practices prevalent in the Academia Class program?

The responses to these questions indicate the extent of success or lack of success of co-Teaching. The main finding indicates that the trainer teachers and the student teachers agreed that there were many advantages to co-teaching and that it contributed to school pupils and the kindergarten children. Thus, it seems that the Academia Class program has an influence beyond mere training processes, on the learning processes in the classes and school pupils. With regard to the advantages of the co-teaching for the school teachers and kindergarten teachers.
\end{abstract}

Keywords: co-teaching, academia class, practicum experiences

\section{Theoretical Background}

Research has investigated student teachers' practicum experiences from various viewpoints. Study of this important issue can produce insights to inform those who plan teacher training for the dynamically changing reality of the 21 st century. Identifying trends in teacher training contributes to the rich current debate underpinning attempts to create optimal teacher training through a tight connection between theory and practice and between academia and fieldwork in schools. Substantive issues in this field are now reviewed, as a background to discussion.

\subsection{Teacher Training}

Throughout the world, teacher-training programs aim to shape a teacher with strong academic abilities and broad knowledge in contents, who is able to cope with the challenges in the field. It was found that the quality of teaching is the most influential factor for the student-teacher's achievements, and that it is directly influenced by the quality of the teacher's experiences. Good, high quality training for student-teachers is essential (Ran, 2018; Rongeldt \& Reining, 2012). Taking these findings in mind, teacher training programs in many world states fall into one of two main conflicting trends. The first: academization in teacher training institutions providing advanced academic degrees to graduates. The second trend: advanced training programs in the field based on clinical experience within schools (Spurling, 2017).

Practical experience of teaching lies at the core of teacher training - learning that takes place in real time in the 
education field. As part of this experience, theoretical knowledge is clarified and interpreted in connection with examples and practical action. This process improves motivation to learn and develop different teaching skills. Significant exposure to teaching practice, accompanied by a training teacher, increases the student teacher's readiness to assume the teacher's role (Maskit \& Mevarech, 2013; Whitford \& Barnett, 2016).

In Israel, there are three main models for teachers' practical training:

(1) The Traditional Model - student teachers are appointed to schools for a one-day (6 hours) experience per week. The pedagogic instructor from the college observes a limited number of the student teacher's lessons and provides feedback over the year. There is no emphasis on the relationship between the college and the school and the choice of locations for the training depends on the training teacher. The student teacher's practice resembles an apprenticeship model, mostly learning from the model that the teacher represents, and less from their own practical teaching experience (Lahav, 2010; Alyan \& Daniel-Saad, 2013).

(2) A Professional Development School (PDS) - in these schools, the student teacher acquires broad experience in selected schools as part of the collaboration between the college and the school. According to the PDS model the student teacher experiences various different types of practical experience while receiving mediation and feedback from the trainer teacher. Additionally, the student-teachers, teachers and teacher trainers participate in developmental and learning processes (Ariav, 2014; Ariav \& Smith. 2006; Maskit \& Mevarach, 2013).

"Academia Class" is a program initiated by the Ministry of Education and now implemented for the fourth year in 30 teacher-training institutions throughout Israel. Approximately 2,000 student teachers participate in the program. Following the success of teacher training programs, a unique training program based on the principles of PDS was formulated. The program focuses the main practical experience on the period at the end of the student-teachers' training (Sperling, 2017) and emphasizes the importance of the continuous and intensive nature of the practicum. The program is performed three days a week in schools and kindergarten, for a total of 12-16 weekly hours. The program emphasizes collaboration between the school and the college and constitutes a substantially different type of practicum from the traditional model, both because of the close guidance of the training teacher, using the practical model of co-teaching and also because of the large scope of responsibility imposed on the student-teachers (Ministry of Education, 2014; Ran, 2018).

Studies which examine the success of the Academia Class program found that it had significant advantages for student-teachers who graduated from the program for their integration in their practicum year and they had a stronger probability of subsequently working in teaching (Macdusi, 2018). Graduates of the program increased their sense of efficacy and were better prepared for the teaching role both in the classroom and in the school organization in comparison to student-teachers' who underwent traditional practicum experience (Eran \& Zaretski, 2017). Teachers who participated in the program expressed their satisfaction with the program and believed that it contributed to all those involved: teachers and student-teachers. They noted that the program contributed to their ability to provide differential responses to their students, in terms of variety of teaching methods, improving their instruction skills and motivation to continue to work in teaching and to learn new things (Arnon \& Presco, 2018). In a study by Rothman and Shmueli (2017) it was found that both student-teachers and teachers - especially in elementary schools - estimated that the contribution of the program to student-teachers was high as expressed in the student-teachers' positive achievements, trainer teachers being open and accessible to the students' queries and use of technological means.

The three models of practicum are based on interaction between the student teacher and the training teacher who guides their practical learning. The extent of the student-teacher's involvement depends on the character of the connection between them. In certain cases, the student-teacher may spend many days passively observing and learning from their observations, until they are allowed gradually to take an active part in the teaching work. In contrast in some cases student-teachers find themselves managing a lesson and the class without any guidance, supervision or instruction from the training teacher. A proper balance between opportunities for different practical experiences and guidance and supervision enables the student-teacher to undergo professional development.

\subsection{Co-Teaching}

Bacharach, Heck and Dank (2004) define co-teaching as a situation in which two teachers (a tutor teacher and a trainee teacher) work together with groups of students from the planning stage, through organization to performance, within the space of a single classroom. Cook and Friend (1995) expand this definition and explain that co-teaching occurs when two teachers or more teach together and provide "substantive instruction to a diverse or blended group of students in a single physical space" (p. 2) Wenzlaff et al. (2002) point up the value added of this type of teaching noting that it would be impossible to teach a lesson with such advantages with a 
single teacher.

There are various possible models of co-teaching: one teacher teaching while the other observes, a main teacher teaching and the other teacher playing a supportive role. "parallel teaching" - teaching the identical lesson simultaneously in two separate groups of student-teachers, "teaching in stations" whereby each teacher teaches different contents to each of the groups, and they alternate between the groups, "changing teachers" where one teacher teaches the whole class while the other teaches a single student or a small teaching group in parallel, and "group teaching" where the teacher and the student-teacher divide their shared responsibility in teaching contents simultaneously to the same group of student-teachers (Bacharach, Heck, \& Dahlberg, 2010; Cook \& Friend, 1995, 2004; Graziano \& Navarrete, 2012; Villa, Navin, \& Thousand, 2004).

Co-teaching became a prevalent strategy when the schools adopted the approach of integrating pupils with disabilities into mainstream classes, and there was an intention to provide an educational response for the pupils with regular development and those with disabilities who studied together. In these cases, the partners were a special education teacher working with a regular education teacher (Friend, Cook, Hurley-Chamberlain, \& Shamberger, 2010).

The use of co-teaching in mainstream education is relatively new (Bacharach, Heck \&Dahlberg, 2010). One of the examples of the use of co-teaching is in teacher training. Co-teaching goes beyond traditional practical experience which involves a hierarchic relation between the student-teacher and training teacher, and becomes a process in which the trainer and the trainee are partners who share the teaching and different areas of responsibility in the classroom. This may take the form of a trainee who observes the trainer or delivers a lesson completely independently or a trainee that undergoes a learning process together with the teacher, experiencing cooperation in the school system and is more prepared for the era of learning and developing educational communities. Guise, Habib, Thiessen, and Robbins (2017) traced the work of eight couples of trainee teachers and teacher trainers, examining the implementation of co-teaching in practical experience. They mapped the common work practices in four main categories along a spectrum from traditional practicum using the model where only one teacher teaches, through a little teaching together, a lot of teaching together and progressive implementation of the model where there was shared planning and work and a dynamic of equal forces between the trainee and the trainer. Nissim and Neifeald (2018) studied the reports of 56 student-teachers and 69 teacher trainers who participated in the "Academia Class" and were instructed to work as co-teachers, investigating the different models applied in their work together. They were able to map the teaching models along a spectrum from traditional practicum without any co-teaching, through low level co-teaching represented by one dominant teacher and an additional supporting/assisting teacher, to synergetic co-practice, in which the student-teacher and trainer teacher worked together in full cooperation, sharing planning, implementation and evaluation. The findings revealed a variety of different models of co-teaching.

\subsection{The Advantages of Co-Teaching}

Co-teaching has various advantages in different areas. Most of the research on this issue relates to the advantages for school pupils, there have been several studies of co-teaching in classes that integrate pupils with difficulties. Murawski (2009) reviewed different studies investigating the contribution of co-teaching to pupils and found that both pupils with disabilities and pupils without any disabilities gained from co-teaching, enjoying longer periods of teacher-student attention, with varied teaching methods and better academic achievements. This was in addition to specific advantages relating to the integration-recognition of diversity and provision of equal opportunities for learning. Thus too, studies conducted in mainstream education found that pupils received far more opportunities for learning and mediation when co-teaching was used. Bacharach, Heck and Dahlberg (2010) found a positive statistical advantage in mathematics and reading achievements among pupils who studied in classes that experienced co-teaching in comparison with pupils in classes with regular teaching by a single teacher.

Research that investigated the advantages for teachers of co-teaching, found that teachers reported increased professional satisfaction and opportunities for professional development that contributed to the improvement of student teachers' achievements (Walther-Thomas, 1997; Weiss \& Brigham, 2000). A study by Gallo-Fox and Scantlebury (2106) noted that trainer teachers applying co-teaching reported that they underwent authentic and meaningful professional development. In another study, Rytivaara and Kershner (2012) indicated that student-teachers who had experienced co-teaching reported that their experience helped to tighten the connection between their theoretical studies and practical work, that through reflection they were able to enjoy reciprocal learning with their trainer and that co-teaching constituted a supportive environment for them to deepen their professional learning. 


\subsection{Practices for Successful Co-Teaching}

Planning, organization and evaluation:

Shared planning of the teaching is very important for co-teaching and appropriate time should be devoted to this issue (Guise et al., 2017; Kamens, Susko \& Elliott, 2013). It was found that the planning should initially be done in very close cooperation between the two teachers but with time the student can take more responsibility for a large part of the planning (Bacharach, Heck \& Dahlberg, 2010). Each of the partners in co-education brings their particular personal skills and abilities to the planning (Murawski \& Lochner, 2011). Following the performance of the teaching, there should be reflection and evaluation of the process and evaluation by the student-teachers. Interpretation and analysis of what occurred clarifies the happenings for the student-teacher and guides them to additional strategies and teaching methods (Scantlebury et al., 2008; Murawski \& Lochner, 2011).

Studies investigating the "Academia Class" program found that the allocation of defined time for the trainee student-trainer teacher meeting constituted a helpful factor for the process (Maskit \& Simon, 2018). Most of the student-teachers and the teachers who participated in the program reported that the meetings between the trainee student and the trainer teacher took place once a week or at a higher frequency. Nevertheless, a minority of the trainee students $(10 \%)$ reported that that these meetings only took place once a month or at an even lower frequency. Prevalent subjects that were discussed in the meetings were evaluation of the trainee student's work, shared learning, organizational matters and also coping with problems of pupils' discipline and behavior (Ratner \& Shmuel, 2017).

Suitable physical structure:

The classroom structure should be suitable for co-teaching to allow the co-teachers to use different models of cooperation. The structure of the classroom can be a significant factor for the success of co-teaching (Kamens, Susko \& Elliott, 2013).

Support for the teachers:

The teacher's willingness and understanding of the model were found to be very important. Teachers who were experienced in co-teaching were more successful in applying co-teaching (Guise et al., 2017). Another factor that mediated and assisted the success of the process in co-teaching of a training teacher and trainee teacher was the guidance of a mentor from the teacher training college (Bacharch, Heck, \& Dahlberg, 2010).

In the "Academia Class" program, appropriate preparation of the trainer teachers and support and guidance by the college were found to correlate with teachers' positive attitudes concerning the program in contrast to a lack of support, vague role definitions and vague division of the work, which were found to be hindering factors for the "Academia Class" program (Arnon \& Presco, 2018; Maskit \& Simon, 2018).

\subsection{Research questions and hypotheses}

1) To what extent does each group of participants in the program estimate that co-teaching methods are advantageous for the teachers/kindergarten teachers, student-teachers and pupils?

2) Which prevalent co-teaching practices used in the Academia Class program?

3) Is there a correlation between the respondents' attitudes concerning the advantages of co-teaching and the practices prevalent in the Academia Class program?

\section{The Research Methodology}

The research was a program evaluation study dealing with the evaluation of a learning program and educational project (Nevo, 1989). It was a quantitative study relying on quantitative data collection and analysis.

\subsection{Research Procedure}

At the end of the academic year 2017, a questionnaire was distributed through Google Drive to the entire list of participants in "Academia Class". They were asked to respond anonymously to the questionnaire and to grade a series of statements on a Likert scale of 1-5. The questionnaire was distributed to 140 student-teachers and 100 trainer teachers and kindergarten teachers participating in the Academia Class program.

\subsection{The Research Population}

125 participants ( 36 general education students, 20 early childhood education students, 51 school teachers and 18 kindergarten teachers) participating in the "Academia Class" program responded to the questionnaires. The student-teachers were all studying in their third year of a bachelor's degree course in education (including early childhood education). $80 \%$ of them were women and $20 \%$ were men. All of them were residents of the North of 
Israel. The school teachers and kindergarten teachers were teaching and training student-teachers in 24 education institutions that were participating in the "Academia Class" project in the academic year 2017 under the auspices of the Ohalo Academic College in Katzrin, Israel, and the Northern region office of the Ministry of Education. The average age of the teachers and kindergarten teachers who responded to the questionnaire was 40 years and they had a mean teaching experience of 13 years. The teachers and kindergarten teachers were all residents of the North of Israel and employed by the Ministry of Education. $85 \%$ of them were women and $15 \%$ of them were men. The distribution of their disciplines is shown in Table 1.

Table 1. The research population/respondents to the questionnaire according to fields of specialization and disciplines

\begin{tabular}{lcc}
\hline Field of specialization/discipline & Student-teachers & Teachers and kindergarten teachers \\
\hline Early childhood education & 20 & 18 \\
Jewish studies & 18 & 2 \\
English & 10 & 16 \\
Sciences & 4 & 19 \\
Maths & 2 & 5 \\
Biology & 2 & \\
Physical Education & & 1 \\
Land of Israel Studies & & 1 \\
Homeroom teaching & & 7 \\
\hline
\end{tabular}

\subsection{Research Instruments}

Three content experts (with a doctorate in education) validated the questionnaire. As noted, it was administered to all participants at the end of the academic year 2017.

The respondents graded a series of eight statements investigating their attitudes concerning the advantages of co-teaching. The statements were graded on a Likert scale of 1-5, whereby the highest value denoted a high level of agreement with the statement. The statements related to three subjects: statements 1-2 related to the advantages for pupils. Statements 3-6 are related to advantages to teachers and statement 7-8 related to advantages for the student-teachers. Statements with even numbers were phrased in negative language and so reversal of scales was performed for them. Means for the responses of each respondent were calculated for the three subjects, so that three measures of advantages were formed. The respondents also graded seven statements expressing their opinion on the practices of co-teaching. These statements were also graded on a Likert scale of 1-5 whereby the highest grade represented a high level of agreement with the statement. These statements were not related to subjects and so there was no need for reversal of the scales, as can be seen in Table 2 .

Table 2. Division of the statements into content categories

\begin{tabular}{|c|c|c|}
\hline Content category & $\begin{array}{c}\text { Statement } \\
\text { number }\end{array}$ & The statement \\
\hline \multirow{2}{*}{ Advantages of the program for pupils } & 1 & $\begin{array}{l}\text { When there are two teachers in a class there is more possibility to } \\
\text { provide help to the pupils }\end{array}$ \\
\hline & 2 & $\begin{array}{l}\text { Although there are two teachers in the class, the pupils do not receive } \\
\text { a larger contribution }\end{array}$ \\
\hline \multirow{4}{*}{$\begin{array}{l}\text { Advantages of the program for teachers and } \\
\text { kindergarten teachers }\end{array}$} & 3 & $\begin{array}{l}\text { There is a contribution to teachers from the co-teaching because they } \\
\text { learn from the student-teachers }\end{array}$ \\
\hline & 4 & $\begin{array}{l}\text { The teacher receives no contribution from the student-teacher in their } \\
\text { joint work }\end{array}$ \\
\hline & 5 & $\begin{array}{l}\text { The co-teaching process contributes to the teachers and they develop } \\
\text { professionally }\end{array}$ \\
\hline & 6 & The teacher gains no professional profit from co-teaching \\
\hline \multirow[b]{2}{*}{ Advantages of the program for student-teachers } & 7 & Co-teaching prepares the student-teacher better for the teaching role \\
\hline & 8 & $\begin{array}{l}\text { There is no advantage for the student-teacher in co-teaching rather } \\
\text { than other models }\end{array}$ \\
\hline Practices of co-teaching & 9 & I plan the lessons together with the trainer teacher \\
\hline
\end{tabular}


10 I and the trainer teacher have a defined time for lesson planning

After each lesson, I and the trainer teacher hold a reflective conversation

After each lesson the trainer teacher gives me feedback, tools and strategies

From the beginning of the year I am an active partner in all that happens in the class

From the beginning of the year I have tried out many learning opportunities

There is a clear division of work between me and the trainer teacher

\section{Findings}

\subsection{Respondents Views on the Program's Advantages}

First, we examined whether there were differences between the four groups of respondents in their measures of the advantages. To do this, ANOVA variance analysis was conducted. Table 3 presents the means and standard deviations for each group regarding the three measures of advantages from the program and also the results of the variance analysis.

Table 3. Mean grades and SDs for views on the advantages of co- teaching, by group and results of variance tests

\begin{tabular}{|c|c|c|c|c|c|c|c|c|c|}
\hline \multirow[b]{2}{*}{ Index } & \multicolumn{2}{|c|}{$\begin{array}{l}\text { Teachers } \\
(\mathrm{N}=51)\end{array}$} & \multicolumn{2}{|c|}{$\begin{array}{c}\text { Students studying general } \\
\text { education } \\
(\mathrm{N}=36)\end{array}$} & \multicolumn{2}{|c|}{$\begin{array}{c}\text { Kindergarten } \\
\text { teachers } \\
(\mathrm{N}=18)\end{array}$} & \multicolumn{2}{|c|}{$\begin{array}{l}\text { Students of early childhood } \\
\text { education }(\mathrm{N}=20)\end{array}$} & \multirow[b]{2}{*}{ F } \\
\hline & Mean & SD & Mean & SD & Mean & SD & Mean & SD & \\
\hline Advantages for pupils & 4.48 & .67 & 4.26 & .91 & 4.56 & .78 & 4.25 & .77 & 1.03 \\
\hline $\begin{array}{l}\text { Advantages for trainer } \\
\text { teachers }\end{array}$ & 3.87 & .65 & 3.46 & .98 & 4.03 & .81 & 4.05 & .85 & $3.37 *$ \\
\hline $\begin{array}{l}\text { Advantages } \\
\text { student-teachers }\end{array}$ & 4.39 & .74 & 3.71 & 1.19 & 4.44 & .95 & 4.00 & 1.19 & $4.06^{* *}$ \\
\hline
\end{tabular}

It was found that the kindergarten teachers gave far higher grades (4.56) for the advantages for kindergarten children from co-teaching than did the other three groups, followed by the teachers (4.48). In contrast, the students studying general education (4.26) and students studying early childhood (4.25) gave a lower grade for the advantages of co-teaching for their pupils. Nevertheless the variance between the groups was not significant $\mathrm{F}(3,121)=1.03, \mathrm{p}>0.5$.

With regard to the advantages for trainer teachers and kindergarten teachers, it was found that the students studying early childhood education (4.05) and the kindergarten teachers gave higher grades for the advantages of co-teaching for teachers. This was in contrast to the school teachers (3.87) and students studying general education (3.46) who gave lower grades to the advantages of co-teaching for teachers. These differences were found to be significant $F(3,121)=3.37, \mathrm{p}<0.05)$.

With regard to the advantages for the student-teachers, the kindergarten teachers (4.44) and the teachers (4.39) gave higher grades for the advantages for student-teachers in co-teaching, while the students studying early childhood education (4.00) and the students studying general education (3.71) gave lower grades for this statement. These differences were found to be significant: $F(3,121)=4.06, p<0.01$. 


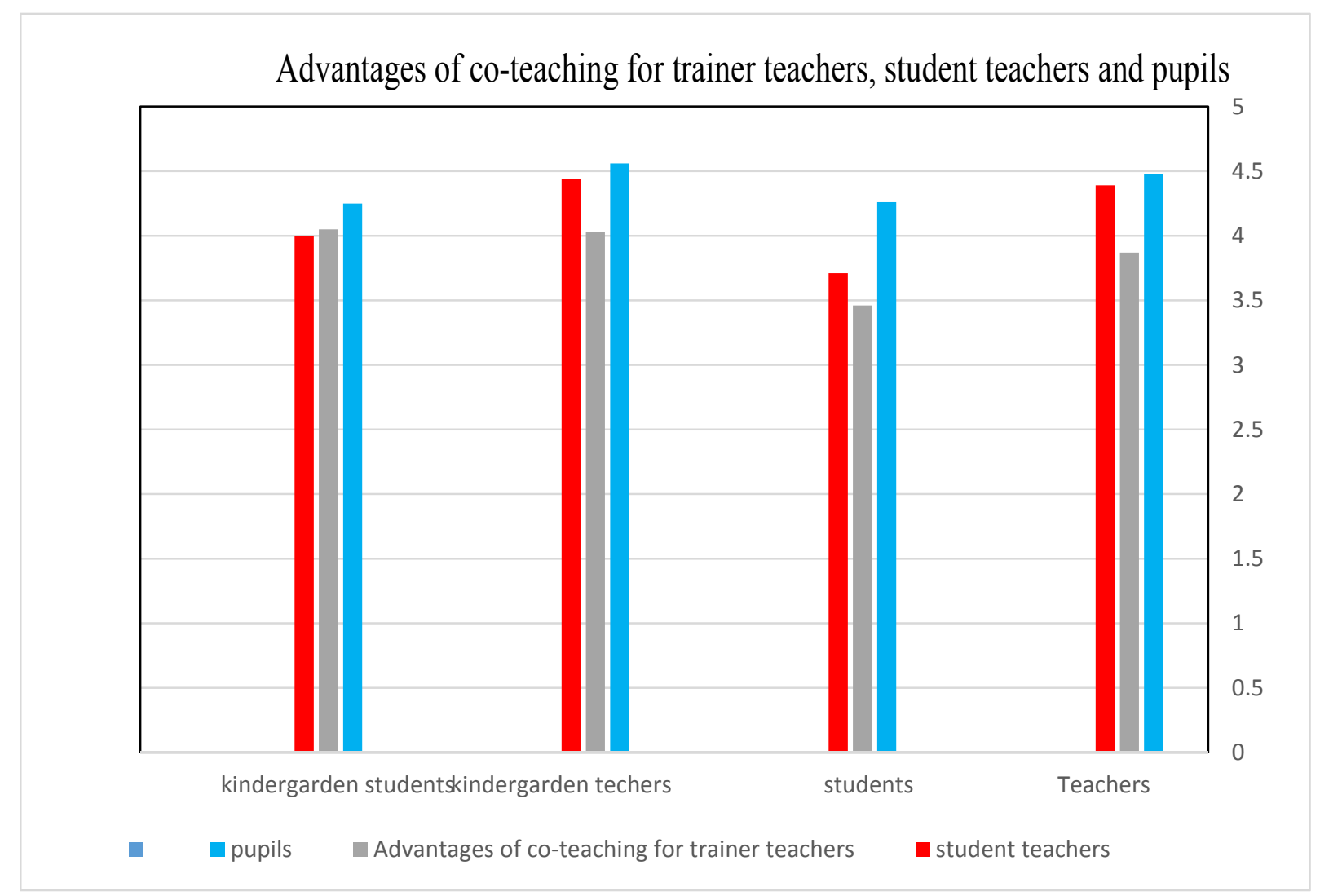

Figure 1. Advantages of co-teaching for trainer teachers, student teachers and pupils

T-tests were performed to test differences between the views of the teachers and the student-teachers. No significant differences were found with regard to the advantages of co-teaching for the pupils: $t(85)=1.28$, $p>0.05$. In contrast it was found that trainer teachers graded the advantages of co-teaching for teachers higher than the student-teachers in a significant manner: $\mathrm{t}(56)=2.21, \mathrm{p}<0.05)$. It was also found that the teachers felt that the advantage to student-teachers was greater than did the student-teachers in a signficant manner: $t(54)=3.06$, $\mathrm{p}<0.01$.

Similarly, t-tests were performed to test the differences between the views of the kindergarten teachers and those of the students studying early childhood education. These tests found no significant differences regarding advantages of co-teaching for the pupils: $\mathrm{t}(36)=0.08, \mathrm{p}>0.05$, with regard to the advantages for trainer teachers: $t(36)=1.21, p>0.05$, or with regard to advantages for student-teachers: $t(36)=1.26, p>0.05$.

When differences were tested between respondents working in schools (teachers and general education students) and respondents working in kindergartens (kindergarten teachers and early childhood education students), the following results emerged as shown in Table 4.

Table 4. Differences regarding the advantages of co-teaching between respondents working in schools and kindergartens (results of t-tests)

\begin{tabular}{lccccc}
\hline & \multicolumn{3}{l}{ Kindergarten $(\mathrm{N}=56)$} & \multicolumn{3}{l}{ School $(\mathrm{N}=69)$} & \\
\hline Index & Mean & $\mathrm{SD}$ & Mean & $\mathrm{SD}$ & $\mathrm{t}$ \\
\hline Advantages for pupils & 4.50 & 0.70 & 4.26 & .91 & 1.73 \\
Advantages for trainer teachers & 3.91 & 0.69 & 3.46 & .98 & 1.58 \\
Advantages for student-teachers & 4.41 & 0.80 & 3.71 & 1.19 & $3.20^{* *}$ \\
\hline
\end{tabular}

T-tests found no significant differences between trainer teachers' and student-teachers' views regarding the advantages for pupils between those who worked in the schools and those who worked in the kindergartens: $t(123)=1.73, p>0.05$. There was also no significant difference between the views of those who worked in schools 
and those who worked in kindergartens regarding the advantages of co-teaching for teachers: $t(96)=1.59$, $p>0.05$. In contrast, it was found that those who worked in schools gave higher grades to the advantages of co-teaching for student-teachers (4.41) than did those who worked in kindergartens (3.71) and in a significant manner: $\mathrm{t}(92)=3.20, \mathrm{p}>0.01$.

In order to examine whether there were differences between the respondents regarding the practices of co-teaching, additional ANOVA tests were performed. The results appear in Table 5.

Table 5. Practices of co-teaching according to the different population groups (ANOVA results)

\begin{tabular}{|c|c|c|c|c|c|c|c|c|c|}
\hline \multirow[b]{2}{*}{ Statement } & \multicolumn{2}{|c|}{$\begin{array}{c}\text { School } \\
\text { Teachers } \\
(\mathrm{N}=51)\end{array}$} & \multicolumn{2}{|c|}{$\begin{array}{l}\text { Education students } \\
\qquad(\mathrm{N}=36)\end{array}$} & \multicolumn{2}{|c|}{$\begin{array}{c}\text { Kindergarten } \\
\text { teachers }(\mathrm{N}=18)\end{array}$} & \multicolumn{2}{|c|}{$\begin{array}{l}\text { Early childhood } \\
\text { students }(\mathrm{N}=20)\end{array}$} & \multirow[b]{2}{*}{$\mathrm{F}$} \\
\hline & $\mathrm{M}$ & SD & $\mathrm{M}$ & SD & $\mathrm{M}$ & SD & M & SD & \\
\hline Shared planning of the lessons & 3.39 & 1.13 & 2.94 & 1.41 & 3.67 & 1.14 & 3.55 & 1.05 & 1.95 \\
\hline Defined time for lesson planning & 3.27 & 1.36 & 2.61 & 1.68 & 3.50 & 1.42 & 3.15 & 1.27 & 2.06 \\
\hline Reflective conversation after each lesson & 3.71 & 1.33 & 3.11 & 1.47 & 4.33 & .59 & 3.35 & 1.35 & $3.94 *$ \\
\hline $\begin{array}{l}\text { Feedback, tools and strategies provided } \\
\text { after each lesson }\end{array}$ & 3.90 & 1.33 & 3.39 & 1.44 & 4.44 & .62 & 3.65 & 1.35 & $2.90^{*}$ \\
\hline $\begin{array}{l}\text { Student-teacher is an active partner in all } \\
\text { that happens in the class }\end{array}$ & 3.33 & 1.24 & 3.33 & 1.57 & 4.11 & 1.23 & 4.00 & 1.17 & 2.59 \\
\hline $\begin{array}{l}\text { Student-teacher tries many learning } \\
\text { experiences }\end{array}$ & 3.65 & 1.26 & 3.42 & 1.46 & 4.22 & 1.26 & 4.00 & 1.26 & 1.85 \\
\hline $\begin{array}{l}\text { Clear work division between } \\
\text { student-teacher and teacher }\end{array}$ & 3.69 & 1.21 & 3.39 & 1.40 & 4.22 & .81 & 3.80 & 1.32 & 1.87 \\
\hline
\end{tabular}

The data in Table 5 indicates that there are differences between the four groups regarding the performance of a reflective conversation after each lesson. The kindergarten teachers indicated that they conduct such a conversation (4.33) at a higher level than did the early childhood education students (3.35), school teachers (3.71) or general education students (3.11).

Thus too, differences were found regarding the extent to which feedback was given after each lesson between the four groups. The kindergarten teachers testified that they gave such feedback (4.44) more than did the teachers (3.90), early childhood education students (3.65) and general education students (3.39).

No significant differences were found between the views of the four groups regarding the other statements on co-teaching practices.

T-tests were performed to identify differences between school teachers and the general education students. These tests found no significant differences between the two groups for any of the seven statements. Similarly, t-tests were performed to identify differences between the kindergarten teachers and the early childhood education students. Differences were found between the two groups in relation to the conduct of a reflective conversation after each lesson, whereby the kindergarten teachers testified that they conducted such a conversation more than did the early childhood education students: $\mathrm{t}(27)=2.96, \mathrm{p}<0.01$. Thus too, with regard to providing feedback after each lesson, differences were found between the two groups such that the kindergarten teachers testified that they provided feedback of this sort more than did the early childhood education students: $t(27)=2.37, p<0.05$.

When the differences were tested between respondents working in the schools (teachers and general education students) and those working in kindergartens (kindergarten teachers and early childhood education students, the results shown in Table 6 were produced. 
Table 6. Practices of co-teaching: comparison of views of respondents working in schools and respondents working in kindergartens (t-test results)

\begin{tabular}{lccccc}
\hline & \multicolumn{3}{c}{ School (N=69) } & \multicolumn{3}{c}{ Kindergarten $(\mathrm{N}=56)$} \\
\hline Statement & Mean & SD & Mean & SD & t \\
\hline Shared planning of the lessons & 3.46 & 1.13 & 3.16 & 1.32 & 1.38 \\
Defined time for lesson planning & 3.33 & 1.37 & 2.80 & 1.55 & 2.03 \\
Reflective conversation after each lesson & 3.87 & 1.21 & 3.20 & 1.42 & $2.81 * *$ \\
Feedback, tools and strategies provided after each lesson & 4.04 & 1.21 & 3.48 & 1.40 & $2.37 *$ \\
Student-teacher is an active partner in all that happens in the class & 3.54 & 1.28 & 3.57 & 1.46 & 0.14 \\
Student-teacher tries many learning experiences & 3.80 & 1.28 & 3.63 & 1.41 & 0.72 \\
Clear work division between student-teacher and teacher & 3.83 & 1.14 & 3.54 & 1.37 & 1.27 \\
\hline
\end{tabular}

$* * \mathrm{p}<0.01 ; * \mathrm{p}<0.05$

T-tests found significant differences between the school teachers' and general education students' views and the views of the kindergarten teachers and early education students regarding the existence of reflective conversations after each lesson: $\mathrm{t}(109)=2.81, \mathrm{p}<0.01$. Significant differences were also found between the views of those who worked in schools and those who worked in kindergartens regarding the provision of feedback after each lesson $\mathrm{t}(109)=2.37, \mathrm{p}<0.05$. No significant differences were found between these two groups for the other statements.

\subsection{Correlations}

In order to test whether there were correlations between the views of the respondents concerning the advantages of co-teaching and their views concerning the practices of co-teaching, Pearson correlation coefficients were calculated. The results appear in Table 7.

Table 7. Pearson correlation coefficients between respondents' views on the advantages of co-teaching and their views on co-education practices

\begin{tabular}{|c|c|c|c|}
\hline Statement & $\begin{array}{l}\text { Advantages for } \\
\text { pupils }\end{array}$ & $\begin{array}{l}\text { Advantages for trainer } \\
\text { teachers }\end{array}$ & $\begin{array}{l}\text { Advantages for } \\
\text { student-teachers }\end{array}$ \\
\hline Shared planning of the lessons & $.245 * *$ & $.387 * *$ & $.408 * *$ \\
\hline Defined time for lesson planning & .136 & $.299 * *$ & $.289 * *$ \\
\hline Reflective conversation after each lesson & .151 & $.398 * *$ & $.446^{* *}$ \\
\hline $\begin{array}{l}\text { Feedback, tools and strategies provided after each } \\
\text { lesson }\end{array}$ & $.201 *$ & $.407 * *$ & $.472 * *$ \\
\hline $\begin{array}{l}\text { Student-teacher is an active partner in all that happens } \\
\text { in the class }\end{array}$ & $.350 * *$ & $.443 * *$ & $.388 * *$ \\
\hline Student-teacher tries many learning experiences & $.385^{* *}$ & $.497 * *$ & $.507 * *$ \\
\hline $\begin{array}{l}\text { Clear work division between student-teacher and } \\
\text { teacher }\end{array}$ & $.321 * *$ & $.450 * *$ & $.437 * *$ \\
\hline
\end{tabular}

$* \mathrm{p}<0.05 ; * * \mathrm{p}<0.01$.

As can be seen from the data in Table 7, all the correlations were positive and most were found to be significant. Thus, it can be said that insofar as the respondent noted the advantages of co-teaching as beneficial, then they would also describe varied practices of co-teaching.

\section{Discussion}

Many studies have discussed the issues involved in student-teachers' practical experience as a significant part of the training processes in the fields of education and teaching. The "Academia Class" program is a relatively young program (now in its fourth year) which is expanding to include continually more participants. It was therefore important to clarify the various processes, contributions, attitudes and trends involved in this program from different angles as reported by those who participate in the program. The use of co-teaching methods is also relatively new in the mainstream education system. As Bacharach and Heck \& Dahlberg (2010) note co-teaching marks a shift from traditional practical experience, where there is a hierarchy between trainer teacher and trainee teacher, to a process in which trainers and trainees are partners who share different teaching and different areas 
of responsibility in the classroom. We believe that in a gradual and protracted process, an educational community can be formed to shape the co-teaching, between school teachers and general education students, and between kindergarten teachers and early childhood education students.

This research investigated two meaningful aspects: identification of the extent to which co-teaching contributed to the four groups that participated in the "Academia Class" program, including the trainer staff (teachers and kindergarten teachers) and student-teachers (students studying general education and students studying early childhood education) and pupils.

With regard to Research Question 1: "To what extent does each group of participants in the program estimate that co-teaching methods are advantageous for the teachers/kindergarten teachers, student-teachers and pupils?

It seems from the findings presented above, that all the groups that participated in the program had a high assessment of the advantages of the program. The main finding indicates that the trainer teachers and the trainee students agreed that co-teaching has many advantages and contributes to the success of their pupils.

Thus, the "Academia Class" program has a significant influence, beyond the training processes on the class's pupils and their learning processes. This finding is in line with and realizes the original goals of the "Academia Class", which aimed to reduce the number of pupils in a class, to enable better adapted teaching, going beyond the important contribution to the practical training of teachers and kindergarten teachers (Ministry of Education, 2014).

In a general and well-understood manner, the reports of those who experienced the program, practicing co-teaching in a kindergarten evaluated the level of the program's contribution as higher (regarding the contribution to the training and trainee teachers) than did those practicing co-teaching in schools. We would argue that the learning environment in the kindergartens, the more obvious interaction between the kindergarten teachers and the student-teachers enables the creation of more varied work practices and methods. This situation enables and directs the co-teachers to synergetic teaching. Moreover, the level of collaboration, or in other words the symbiosis between the trainer and trainee teachers is very high, as was noted in our previous research (Nissim \& Neifeald, 2018). On the other hand, it is reasonable to assume that the level of collaboration between the trainer kindergarten teachers and the trainee students studying early childhood education were also high before the "Academia Class" program. As noted, this is because of the unique character of the discipline of early childhood education and the learning environment created in the kindergarten. Kindergarten teachers and the student-teachers they train tend to speak in "a single voice". We therefore argue that in this category, the "Academia Class" has not brought any revolutionary change; rather it has more clearly defined and preserved training and learning practices that would anyway occur under the unique conditions of this discipline.

Thus, the change and the high-level reports concerning advantages for teachers and student-teachers studying general education are all the more powerful, since there a significant change in practicum practices was obvious. This was a change from passive practical experience, as an observer to practice of active collaborative teaching as part of a pair: the trainer teacher and the trainee teacher working together. In the schools, in comparison to the kindergartens, the practicum experience is completely different, deconstructing traditional paradigms and constructing new learning processes and practices. Established concepts were shattered and rebuilt in line with the clear requirements and the "Academy Class" guidelines for teacher training processes. These findings are supported by current studies in the field, which noted that teachers who participated in the program expressed satisfaction and believed that it contributed to all those involved - teachers and students (Arnon \& Presco, 2018).

Noting the advantages for the trainee teachers that were reported by the trainer teachers, we suggest that these reports were influenced by several parameters that characterize the trainer teachers, these include: their mature age and many years of experience in training student-teachers. In other words, they are able to see the advantages of the program through the lens of that rich experience. These findings are supported by earlier studies, which indicate the advantages of co-teaching for teachers who reported that professional bonding led to increased professional satisfaction, opportunities for professional growth, personal support and opportunities for cooperation, all of which helped to improve the pupils' achievements (Walther-Thomas, 1997; Weiss \& Brigham, 2000). The trainer teachers practicing co-teaching with trainee student-teachers reported that they experienced authentic and meaningful professional development. Their daily interaction necessitated continuous discussion and reflection on teaching, they introduced new curricular resources and this encouraged the trainer teachers to expand their roles as leaders and teacher educators in the school (Gallo-Fox \& Scantlebury, 2016). Student-teachers who experienced co-teaching with a trainer teacher reported that this experience helped them to understand the connection between theory and practice, that the reflection enabled them to enjoy reciprocal learning and co-teaching constituted a supportive environment for deep professional learning (Rytivaara \& 
Kershner, 2012).

In response to Research Question 2: "Which prevalent co-teaching practices are used in the 'Academia Class' program?". According to the findings the categories that received the highest grades were: the student-teacher shares all the processes occurring in the class together with the teacher, the student-teacher experiences all learning opportunities in practice and also the division of work between the trainer teacher and the trainee teacher is clear and well-structured. This finding points to the distinct advantages that all program participants see in the program as expressed in the statements indicating cooperative instruction in the pair, which received the highest score.

These findings correlate with findings from other research in this field indicating that the initial planning process should be conducted in close connection between the trainer teacher and the trainee teacher, but over time, the trainee teacher will take the responsibility for the larger part of the planning (Bacharach, Heck \& Dahlberg, 2010). Moreover, the feedback and reflection conversation is most significant and it is recommended that after the teaching reflection and evaluation of the teaching process, assessment of the value of the process for the pupils should take place (Scantlebury et al., 2008; Murawski \& Lochner, 2011).

In response to Research Question 3: "Is there a correlation between the attitude of the respondents concerning the advantages of co-teaching and the implementation of prevalent practices in the Academia Class program? The tests and other findings revealed that all the correlations (between respondents' views on advantages of co-teaching and description of co-teaching practices) were positive and significant, so that it appears that insofar as the respondents were able to see the advantages of co-teaching, then they were also able to describe the use of varied practices in co-teaching. The principle of reciprocity acted here so that insofar as the respondent held a positive view of co-teaching then they would demonstrate efforts to teach with a variety of practices and methods. However, it is also true that a teacher and student-teacher who entered the program and were instructed to work as co-teachers and to assimilate varied practices would gradually form a positive opinion of the contribution of co-teaching for the pupils, student-teacher and teacher as they experience this teaching method in practice. Thus, it seems that most of the program's participants saw the advantages in co-teaching, which had a clear and significant influence on the variety of teaching practices used.

The two categories that were investigated: the contribution to the program's participants and the collaborative teaching practices indicate the success of the program as a program that makes a meaningful positive contribution. However, this is the first evaluation study of its kind, intended to provide a sort of mid-term feedback on the implementation of the program. This means that there is still a long way to go to reach more generalizable insights. It is planned to expand the program for a further period and to more colleges in order to reach more extensive conclusions .

\section{Conclusions and Recommendations}

The participants in the "Academia Class" agreed that co-teaching provided a significant contribution for the school pupils .

The program provided a significant contribution to the reciprocal relations between the kindergarten teachers and early childhood education students.

The program provided a large contribution to general education students and their trainer teachers .

Co-teaching enables a large range of teaching practices to be employed including: a partnership between the student-teacher and the teacher in all the processes that occur in the classroom, share planning of time and tasks, planning feedback conversations, reflective thinking and evaluation of the teaching. Thus, the contribution of co-teaching is significant for all those involved, enabling the use of a wide range of teaching practices, something that without co-teaching would be difficult to perform.

In light of our findings, we recommend:

1) Broaden the program's scope and to continue it for several more years.

2) To broaden the research on the program and to observe additional influences it may have, for example, the systematic assimilation of practices over the coming years.

3) To establish co-teaching in a structured, guided and directed manner through supplementary courses and emphasis on academic-pedagogic supervision.

4) To broaden research to relate to additional issues that emerge from clinical practice, observing the position and reports of the pupils and their views of the contribution they received from the program, the contribution to the school etc. Such research should also throw some light on the Academia Class in general 
and on co-teaching in particular.

\section{The Limitations of the Research}

Despite the contributions discussed above, this study's limitation is its focus on one specific research population. This convenience model was chosen in advance, in order to learn, observe, and come to conclusions regarding work in the field, we set the program's didactic goals, and other administrative goals for ourselves as the program directors. Therefore, it seems relevant to expand the study to future cohorts within this program, in order to examine the trends of co-teaching in a focused and longitudinal manner and identify the possible significance for this approach. The research population was not divided in a symmetrical way and there was not an identical number of respondents answering each category of the questionnaire.

\section{References}

Alyan, S., \& Daniel-Saad, A. (2013). Transition from the traditional model of practical experience to a cooperative model - slogan or the need of the hour? Dafim - Journal of Theory and Research in Education, 56, 35-59. [Hebrew]

Ariav, T., \& K. Smith (2006). Creating collaboration between teacher training institutions and the field: An international view of the emphasis on school models for professional development (PDS). In M. Zilberstein, M. Ben-Peretz, \& N. Greenfeld (Eds.), New trends in training programs for teachers: Cooperation between colleges and schools - The Israeli story (pp. 21-67). Tel Aviv: MOFET Institute. [Hebrew]

Ariav, T. (2014). Practical experience in teacher training: "Rethinking the course". MOFET Institute Journal, 53, 13-19. [Hebrew]

Arnon, R., \& Presco, B. (2018). The Academia Class program from the perspective of the trainer teacher. Presented at the Day Seminar on the subject: Research on the "Academia Class" program. Tel Aviv: MOFET Institute. [Hebrew]

Bacharach, N. L., Heck, T. W., \& Dahlberg, K. (2010). Changing the face of student teaching through co-teaching. Teacher Development Faculty Publications.

Bacharach, N., Heck, T., \& Dank, M. (2004). Co-Teaching in student teaching: A case study. Paper presented at the Annual Meeting of the Association of Teacher Educators, Dallas, Texas.

Cook, L., \& Friend, M. (1995). Co-teaching: Guidelines for creating effective practices. Focus on Exceptional Children, 28(3), 1-17. https://doi.org/10.17161/fec.v28i3.6852

Cook, L., \& Friend, M. (2004). Co-teaching: Principles, practices and pragmatics. Retrieved from http://files.eric.ed.gov/fulltext/ED486454.pdf

Eran, Z., \& Zaretski, R. (2017). The "Academia Class" program advancing self-efficacy in teaching: Comparative research. Miklol, Multidisciplinary Journal, 32, 121-129. [ Hebrew]

Friend, M., Cook, L., Hurley-Chamberlain, D., \& Shamberger, C. (2010). Co-teaching: An illustration of the complexity of collaboration in special education. Journal of Educational and Psychological Consultation, 20, 9-27. https://doi.org/10.1080/10474410903535380

Gallo-Fox, J., \& Scantlebury, K. (2016). Coteaching as professional development for cooperating teachers, Teaching and Teacher Education, 60, 191-202. https://doi.org/10.1016/j.tate.2016.08.007

Graziano, K. J., \& Navarrete, L. A. (2012). Co-teaching in a teacher education classroom: Collaboration, compromise, and creativity. Issues in Teacher Education, 21(1), 109-126.

Guise, M., Habib, M., Thiessen, K., \& Robbins, A. (2017). Continuum of co-teaching implementation: Moving from traditional student teaching to co-teaching. Teaching and Teacher Education, 66, 370-382. https://doi.org/10.1016/j.tate.2017.05.002

Kamens, M. W., Susko, J. P., \& Elliott, J. S. (2013). Evaluation and supervision of co-teaching: A study of administrator practices in New Jersey. NASSP Bulletin, 97(2), 166-190. https://doi.org/10.1177/0192636513476337

Macdusi, A. (2018). From academia to the classroom: Examining a training model and type of integration in teaching in three educational Sectors. Research presented at The Day Seminar on the "Academia Class". Tel Aviv: MOFET Institute. [Hebrew]

Maskit, D., \& Mevarech, Z. (2013). There is another way: Teacher training according to the cooperative-partnership PDS model. Dafim - Journal of Theory and Research in Education, 56, 15-34. 
[Hebrew]

Maskit, D., \& Simon, A. (2018). Trainer teachers'attitudes towards the practical teacher training process: From the picture of the Academia Class. Research presented at the Day Seminar on the subject: Research on the "Academia Class" program. Tel Aviv: MOFET Institute. [Hebrew]

Ministry of Education. (2014). Academia Class-Partnership to reinforce teaching: Policy statement summarizing the think tank [Hebrew]. https://doi.org/10.1002/btpr.5420040411

Murawski, W. W. (2009). Collaborative teaching in secondary schools: Making the co-teaching marriage work! Corwin Press. https://doi.org/10.1108/09578231011015476

Murawski, W. W., \& Lochner, W. W. (2011). Observing co-teaching: What to ask for, look for and listen for. Intervention in School and Clinic, 46(3), 174-183. https://doi.org/10.1177/1053451210378165

Nissim, Y., \& Naifeld, E. (2018). Co-Teaching in the Academy-Class program: From theory to practical experience. Journal of Education and Learning, 7, 79-91.

Ran, E. (2018). Ground-anchored programs for teacher-training: Teacher programs residency. A survey of selected models. L. Yosefsberg Ben Yehoshua (Ed.) Tel Aviv: MOFET Institute. [Hebrew]

Ratner, D., \& Shmueli, H. (2017). The "Academia Class" program - Findings of evaluation of findings from research in the academic year 2016. Jerusalem: National Authority for Measures and Evaluation in Education. [Hebrew]

Ronfeldt, M., \& Reininger, M. (2012). More or better student teaching? Teaching and Teacher Education, 28(8), 1091-1106. https://doi.org/10.1016/j.tate.2012.06.003

Rytivaara, A., \& Kershner, R., (2012). Co-teaching as a context for professional learning and joint knowledge construction. Teaching and Teacher Education, 28, 999-1008. https://doi.org/10.1016/j.tate.2012.05.006

Scantlebury, K., Gallo-Fox, J., \& Wassell, B. A. (2008). Coteaching as a model for preservice science teacher education. Teaching and Teacher Education, 24(4), 967-981. https://doi.org/10.1016/j.tate.2007.10.008

Sperling, D. (2017). Review of information on the subject of world teacher training programs. L. Yosefsberg Ben-Yehoshua (Ed.) Tel Aviv: MOFET Institute. [Hebrew]

Villa, R. A., Nevin, A. I., \& Thousand, J. S. (2004). A guide to co-teaching. New York: Corwin Press.

Walsh, J. M., \& Jones, B. (2004). New models of cooperative teaching. Teaching Exceptional Children, 36(5), 14-20. https://doi.org/10.1177/004005990403600502

Walther-Thomas, C. S. (1997). Co-teaching experiences: The benefits and problems that teachers and principals report over time. Journal of learning disabilities, 30(4), 395-407. https://doi.org/10.1177/002221949703000406

Weiss, M. P., \& Brigham, F. J. (2000). Co-teaching and the model of shared responsibility: What does the research support? Advances in learning and behavioral disabilities, 14, 217-246.

Wenzlaff, T., Berak, L., Wieseman, K., Monroe-Baillargeon, A., Bacharach, N., \& Bradfield-Kreider, P. (2002). Walking our talk as educators: Teaming as a best practice. In E. Guyton. \& J. Ranier (Eds.), Research on meeting and using standards in the preparation of teachers (pp. 11-24). Dubuque, IA: Kendall-Hunt Publishing.

Whitford, E. V., \& Barnett, B. E. (2016). The professional development school approach to teacher education: Identification of a model. In Conference Proceedings. The Future of Education (pp. 457-460).

\section{Copyrights}

Copyright for this article is retained by the author(s), with first publication rights granted to the journal.

This is an open-access article distributed under the terms and conditions of the Creative Commons Attribution license (http://creativecommons.org/licenses/by/4.0/). 